\title{
Prey selection mechanism of ambush-foraging hydromedusae
}

\author{
Charlotte Regula $^{1}$, Sean P. Colin ${ }^{1, *}$, John H. Costello ${ }^{2}$, Heather Kordula ${ }^{1}$ \\ ${ }^{1}$ Environmental Science/Marine Biology, Roger Williams University, Bristol, Rhode Island 02908, USA \\ ${ }^{2}$ Biology Department, Providence College, Providence, Rhode Island 02918, USA
}

\begin{abstract}
The widespread occurrence and frequent abundance of small hydromedusae suggests that they may play an important role in planktonic communities. However, rather than exhibiting dominant impacts on any specific planktonic group, field studies have demonstrated diverse dietary niches and only modest trophic impacts by small hydromedusae. To understand the functional bases for these patterns, we exposed 2 hydromedusae (Cladonema californicum and Leuckartiara sp.) to a variety of prey types (dinoflagellates, rotifers, barnacle nauplii, copepods and the hydromedusa Obelia sp.) while video-recording predation sequences (encounter, capture, ingestion). Both C. californicum and Leuckartiara sp. ambush prey and possess penetrating nematocysts (stenoteles and euryteles, respectively). Although similar prey selection patterns might be expected based on encounter models or nematocyst complements, the 2 species exhibited some markedly different ingestion patterns. For example, C. californicum positively selected copepod prey and negatively selected hydromedusae, whereas Leuckartiara sp. exhibited the opposite pattern. Quantification of predation sequences demonstrated that hydromedusan dietary variations resulted from speciesspecific differences in prey capture efficiencies as well as efficiencies in post-capture transfer to the gut. Species-specific prey selection patterns and limited ingestion capacities may explain the diverse prey selection patterns and limited trophic significance observed in field studies of ambush-foraging hydromedusae.
\end{abstract}

KEY WORDS: Functional morphology $\cdot$ Jellyfish feeding $\cdot$ Omnivory $\cdot$ Predation $\cdot$ Anthomedusae Cnidae $\cdot$ Capture mechanisms

\section{INTRODUCTION}

Medusae are important planktivorous predators capable of structuring pelagic ecosystems (Matsakis \& Conover 1991). However, the species that demonstrably impact prey populations are almost exclusively large medusae which forage as cruising predators. In contrast, species which feed as ambush predators have not been found to substantially impact prey populations (Matsakis \& Conover 1991, Costello \& Colin 2002, Hansson et al. 2005). The relatively low trophic influence of ambushforaging hydromedusae is surprising in light of their frequently high seasonal abundances (Matsakis \& Conover 1991, Toyokawa \& Terazaki 1994). In contrast to larger, cruising scyphomedusan predators (e.g. Costello \& Colin 1994, Dabiri et al. 2005, Titelman \& Hansson 2006), the mechanistic basis of predation by small, ambush-foraging hydromedusae has received less attention (Hansson \& Kiørboe 2006a,b). However, the different foraging modes of ambush medusae relative to cruising medusae suggest that different mechanisms may be involved during predation, with correspondingly different predatory impacts.

Past studies on ambush-foraging hydromedusae have focused on field and laboratory gut content analysis or incubation experiments (Purcell 1981, Matsakis \& Conover 1991, Costello \& Colin 2002, Hansson \& Kiørboe 2006a). Since these approaches do not provide insight into the controlling events that result in prey capture, they do not enable prediction of trophic interactions outside the limited experimental conditions, nor provide wider generalizations applicable to the large number of unstudied ambush-foraging hydromedusae. 
A more detailed description of the components of predation during the ambush process may help resolve several enigmatic traits of prey selection characteristics of these medusae. For example, all ambush medusae feed by remaining motionless (either while drifting through the water column or remaining attached to a substrate) waiting for prey to collide with their extended tentacles (Passano 1973, Mills 1981, Greene 1986, Madin 1988, Hansson \& Kiørboe 2006b). Predation theory would suggest that ambush-foraging medusae should encounter and capture the fastest, most abundant prey (Gerritsen \& Strickler 1976, Pastorok 1981, Purcell 1981, Greene 1983, Costello \& Colin 2002). However, gut content studies have shown different species to have largely non-overlapping diets indicating specific prey selection patterns (Costello \& Colin 2002). This pattern of prey partitioning by cooccurring ambush medusae implies that mechanisms besides encounter rates are important for determining the diets of ambush-foraging medusae.

The goal of the present study was to quantify predator-prey interactions of 2 ambush foraging medusae (Cladonema californicum and Leuckartiara sp.; Fig. 1) fed an array of different prey items to arrive at a more general understanding of the factors important in determining prey selection in ambush-foraging medusae. The 2 species have different prey selection patterns: C. californicum is a strong copepod predator (Costello 1988) and Leuckartiara sp. feeds primarily on other hydromedusae (Purcell 1991). We quantified the efficiency with which the medusae capture, transfer and ingest different prey items to determine which steps in the predator-prey interaction process are important for determining interaction outcomes. These observations are then considered in

\section{Cladonema californicum Leuckartiara sp.}

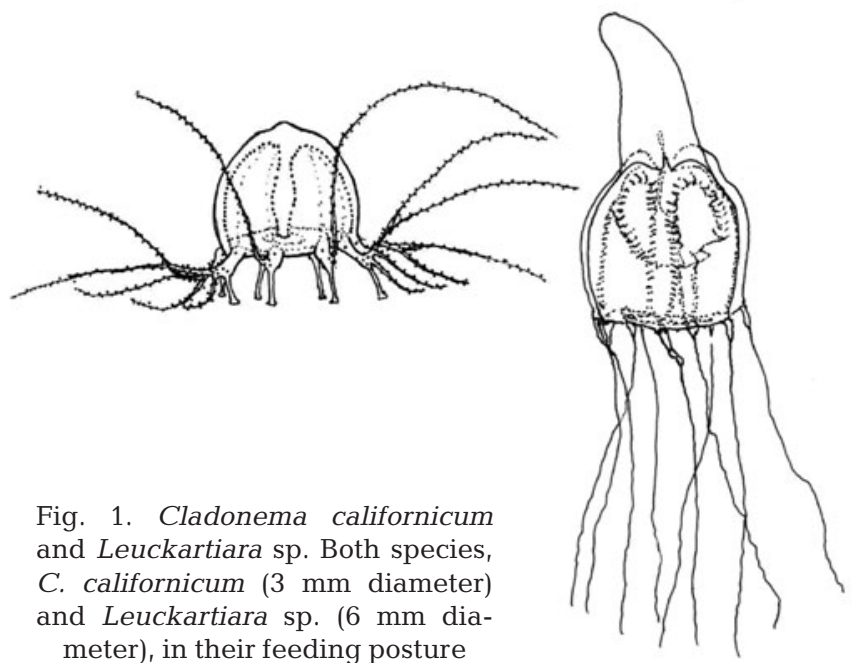

conjunction with an analysis of nematocyst properties in order to evaluate whether differences in the type and arrangement of nematocysts between the medusan species are consistent with differences in how they interact with prey.

\section{MATERIALS AND METHODS}

Experimental organisms. The hydromedusan species used in the present study, Cladonema californicum (bell size from 2 to $3 \mathrm{~mm}$ ) and Leuckartiara sp. (bell size from 3 to $5 \mathrm{~mm}$ ), were generously provided by the New England Aquarium, Boston, Massachusetts, USA. C. californicum forages as a benthic ambush medusa attached to substrates, while Leuckartiara sp. is a pelagic ambush forager that drifts in the water column (Fig. 1). While each species occupies different habitats and may encounter different prey species in nature, we used them as models of ambushforaging medusae and believe the mechanisms that determine the fate of their post-encounter interactions with prey will be applicable to other ambush-foraging species regardless of their habitat.

In the laboratory, medusae were maintained in 11 glass containers at a density of 8 to 10 ind. container ${ }^{-1}$. The containers were placed on rolling platforms (1 rpm) and kept at a constant temperature of $13^{\circ} \mathrm{C}$ in a diurnal light cycle. This setup was an effective way to maintain the medusae long-term by keeping them suspended and preventing them from aggregating on the bottom of vessels where bacteria can damage the tentacles and bell of medusae.

Filming setup. Predator-prey interactions were videotaped using the 2-dimensional micro-videographic techniques described by Colin et al. (2005), where $1000 \mathrm{ml}$ glass filming vessels, containing filtered seawater, were side-lit using infrared light emitting diodes (wavelength $=850 \mathrm{~nm}$ ). The infrared illumination prevented phototactic prey from aggregating along the sides of the filming vessel and maintained a relatively even distribution of prey throughout the vessel. Size scales were recorded for each predator by placing a ruler inside the vessel. Sequential frames, at a rate of 60 frames $\mathrm{s}^{-1}$ (fps), were marked with a time/ date recorder. Each videotaped incubation lasted approximately 15 to $60 \mathrm{~min}$, depending on the number of predator-prey interactions that were observed during videotaping. Cladonema californicum ( $\mathrm{n}=31$ ) were allowed to settle onto a raised platform within the vessel, while Leuckartiara sp. (n = 28) were gently tethered using a micropipette tip suctioned to the apex of the bell. Video recordings of behavioral interactions that occurred during video sequences were analyzed frame-by-frame using Adobe Premiere. 
Predation components. In order to observe and quantify interactions between the hydromedusae and their prey, individual hydromedusan predators were exposed to a variety of different prey. These included the hydromedusae Eutonina sp. and Obelia sp. (length $\pm \mathrm{SD}=2.5 \pm 0.6 \mathrm{~mm})$, barnacle nauplii $(0.90 \pm$ $0.1 \mathrm{~mm})$, copepod Acartia hudsonica adults (1.1 \pm $0.1 \mathrm{~mm})$ and nauplii $(0.35 \pm 0.1 \mathrm{~mm})$, brine shrimp Artemia sp. nauplii $(0.67 \pm 0.2 \mathrm{~mm})$, rotifers Brachionus sp. $(0.34 \pm 0.09 \mathrm{~mm})$ and dinoflagellates Lingulodinium sp. $(0.05 \pm 0.01 \mathrm{~mm})$. The barnacle nauplii, copepods, Artemia sp. nauplii and rotifers were combined into mixed diets to provide estimates of prey selection. The dinoflagellates and hydromedusae were provided only as single prey diets to supplement the size variation of prey examined.

Predator-prey interactions were quantified by breaking the predation process into the component steps of encounter, capture, transfer and ingestion (Holling 1959) (Fig. 2) for interactions with different prey types. Encounter referred to actual contact between a prey and medusan tentacles. Capture occurred when a prey item was retained on the tentacles, even if briefly. Ingestion occurred after prey were transferred from a tentacle to the mouth and then finally consumed. Capture efficiency was quantified as (no. captured/no. encountered), transfer efficiency as (no. of transferred/no. captured), and ingestion efficiency as (no. ingested/no. encountered). Prey handling time was measured as the elapsed time from prey capture to tentacle redeployment following ingestion.

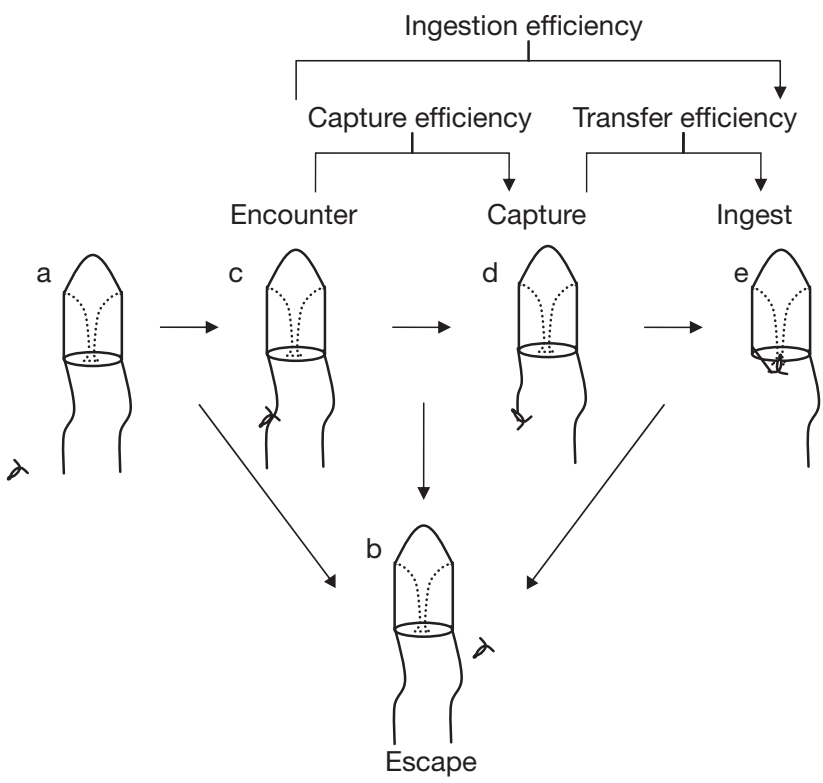

Fig. 2. Cladonema californicum and Leuckartiara sp. Observed sequence of events during the feeding process of $C$. californicum and Leuckartiara sp., and illustration of terms
Non-parametric Kruskal-Wallis tests were used to compare the different efficiencies among the prey types. All tests showed that the efficiencies differed among prey types $(p<0.05)$. The Mann-Whitney Rank Sum test was then used to make post-hoc comparisons between 2 specific prey types. Comparisons of efficiencies between Cladonema californicum and Leuckartiara sp. were made using the Mann-Whitney Rank Sum test.

Prey selection was quantified for the mixed diet studies using Pearre's (1982) electivity index, $C_{\text {, }}$ where:

$$
C= \pm\left(\chi^{2} / z\right)^{1 / 2}
$$

This electivity index depends on the chi-square examination of the amounts of the individual prey taxa ingested in relation to the number of available prey taxa $(z)$ within the experiment. Ingestion rates were based on observed ingestions that occurred over a $1 \mathrm{~h}$ incubation period. Positive and negative $C$ values significantly different from zero indicate selection for and against prey, respectively.

Nematocyst quantification. Medusae tentacles were analyzed to identify the different types of nematocyst present and their distribution on the tentacles. Tentacles of Cladonema californicum $(\mathrm{n}=10)$ and Leuckartiara sp. $(n=7)$ were flattened onto slides with a coverslip and imaged using a TE2000-U Nikon inverted microscope at $90 \times$ magnification with oil emersion. This allowed tentacles to be viewed 2-dimensionally, enabling nematocysts to be seen on all sides of the tentacle. Still images were taken using a 7 megapixel Canon Powershot digital camera, and digital still images were analyzed using Image-J software. The nematocyst characteristics measured were: capsule length and width, tubule length and nematocyst density.

\section{RESULTS}

\section{Feeding mechanism and efficiencies}

Cladonema californicum and Leuckartiara sp. displayed the typical feeding behavior described for tactile ambush-foraging medusae (Mills 1981) (Fig. 2). Interactions with prey were initiated by prey swimming or drifting into an extended tentacle (Fig. 2c). Depending on the prey type, encounters were followed by contraction of the tentacle with attached prey (Fig. 2d) or by prey escape from the tentacle (Fig. 2b). Capture events were followed either by transfer of the prey to the mouth and then ingestion (Fig. 2e) or by prey escape from the tentacle (Fig. 2b). When the gut of the medusae was full, prey remained on the tentacle for a prolonged period of time (Fig. 2d). 
Cladonema californicum and Leuckartiara sp. exhibited different feeding patterns. C. californicum retained the large crustaceans (i.e. copepods and Artemia sp.) better than Leuckartiara sp. (Mann-Whitney Rank Sum test, comparison between medusae for transfer efficiencies of adult copepods and Artemia sp., p < 0.05), while Leuckartiara sp. was more effective at ingesting hydromedusae $(\mathrm{p}<0.05)$.

Cladonema californicum was most effective at ingesting Artemia sp. nauplii and copepod adults and nauplii (Mann-Whitney Rank Sum test, comparisons between Artemia sp., nauplii and adult copepods, p > 0.05 ; comparisons between these prey and the other prey types, $\mathrm{p}<0.05$ ) (Fig. 3c). They did not ingest barnacle nauplii effectively and never ingested hydromedusae, rotifers or dinoflagellates. Barnacles were not ingested because they were poorly retained on the tentacles and rarely transferred to the mouth (comparison between transfer efficiencies, $p<0.02$ ). Hydromedusae, rotifers or dinoflagellates were not ingested because $C$. californicum did not respond to encounters with these prey and, consequently, did not capture them (Fig. 3a). In fact, rotifers and dinoflagellates were observed swimming along tentacles and frequently bouncing into them without being harmed or even reacting. Accordingly, in the mixed diets $C$. californicum positively selected for only Artemia sp. and copepods (Fig. 4).

Leuckartiara sp. was also most effective at capturing, transferring and ingesting Artemia sp. nauplii and small hydromedusae (Fig. 5) (Mann Whitney Rank Sum test, comparing capture, transfer and ingestion efficiencies to all other prey types except hydromedusae, $\mathrm{p}<0.02$ ). While they were able to capture barnacle nauplii and copepods they did not retain them as well and most escaped before transfer (comparison of Artemia sp. and hydromedusae to all other prey types, p < 0.05) (Fig. 5c). Leuckartiara sp. did not respond to or capture rotifers and dinoflagellates (Fig. 5c). When presented with the mixed diets, Leuckartiara sp. only positively selected for Artemia sp. nauplii (Fig. 4b).

Leuckartiara sp. were highly effective at capturing and ingesting small hydromedusae, but at the high encounter rates of our laboratory study their overall ingestion rates were limited by gut capacities. Leuckartiara sp. guts filled after ingesting 1 or 2 hydromedusae. Consequently, ingestion efficiencies declined rapidly because captured medusae were not transferred and remained on the tentacle for long durations (regression, $\mathrm{p}<0.05$ ) (Fig. 6). At high prey densities, gut fullness can limit ingestion rate of ambush-foraging medusae so that ingestion rate becomes a function of digestion time (Hansson \& Kiørboe 2006a). The efficiencies presented in Fig. 5 are averages of all of these successive captures and, therefore,
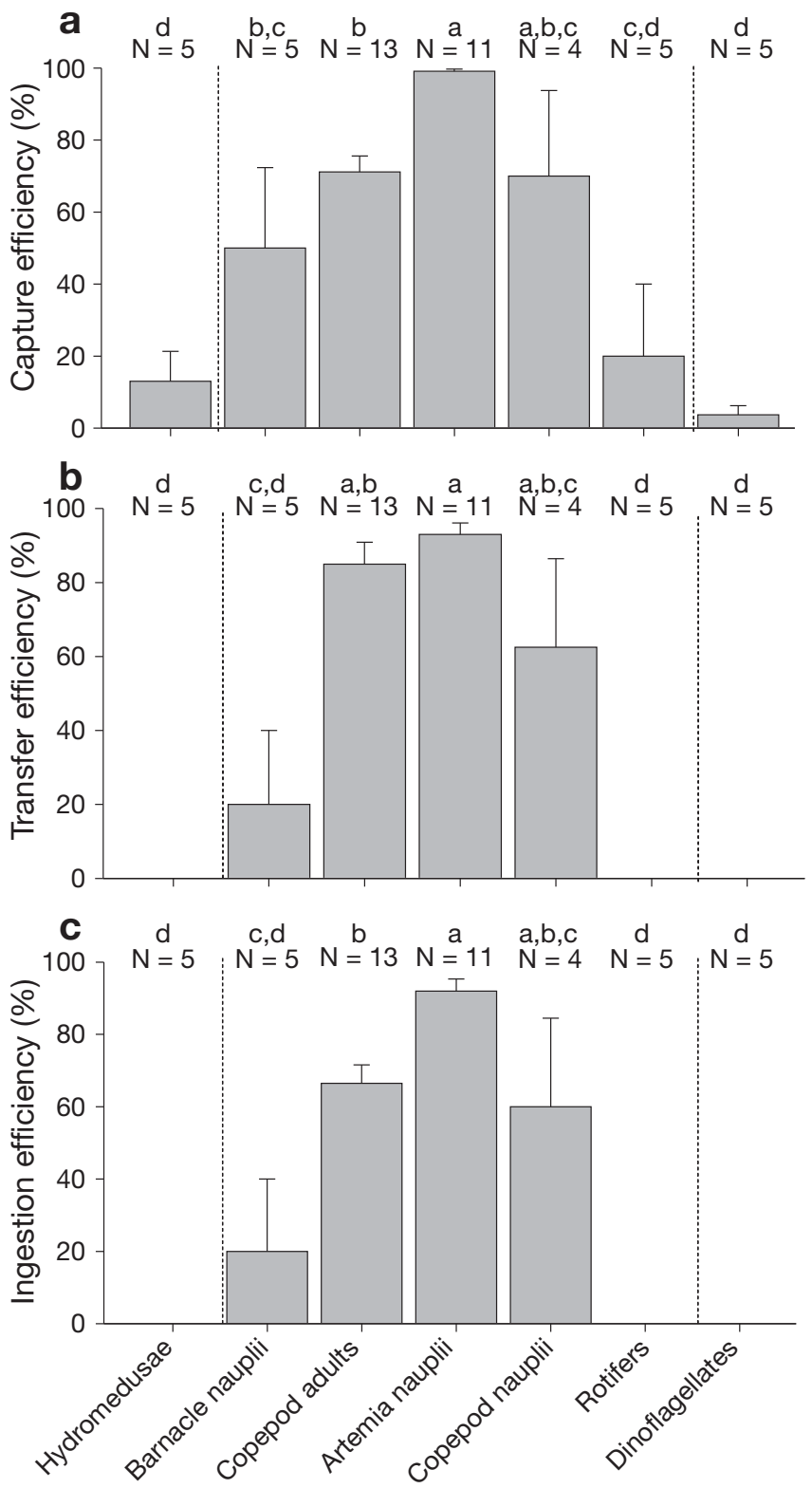

Fig. 3. Cladonema californicum. Average (a) capture efficiencies (prey captured/prey encountered), (b) transfer efficiencies (prey ingested/prey captured) and (c) ingestion efficiencies (prey ingested/prey encountered) of C. californicum fed different prey types. $\mathrm{N}=$ number of medusae observed (observational unit); however, each medusa had several interactions with each prey type. Vertical dashed lines separate prey groups used for each diet; species between lines were a mixed species diet. Efficiencies of prey with the same letter designation did not significantly differ (Mann-Whitney Rank Sum test, $p>0.05)$. Error bars represent SE

lower than the efficiencies of Leuckartiara sp. fed small hydromedusae when they had empty guts. Consistent with these feeding studies, previous observations have identified Leuckartiara sp. as a predator of medusae (Purcell 1991). 


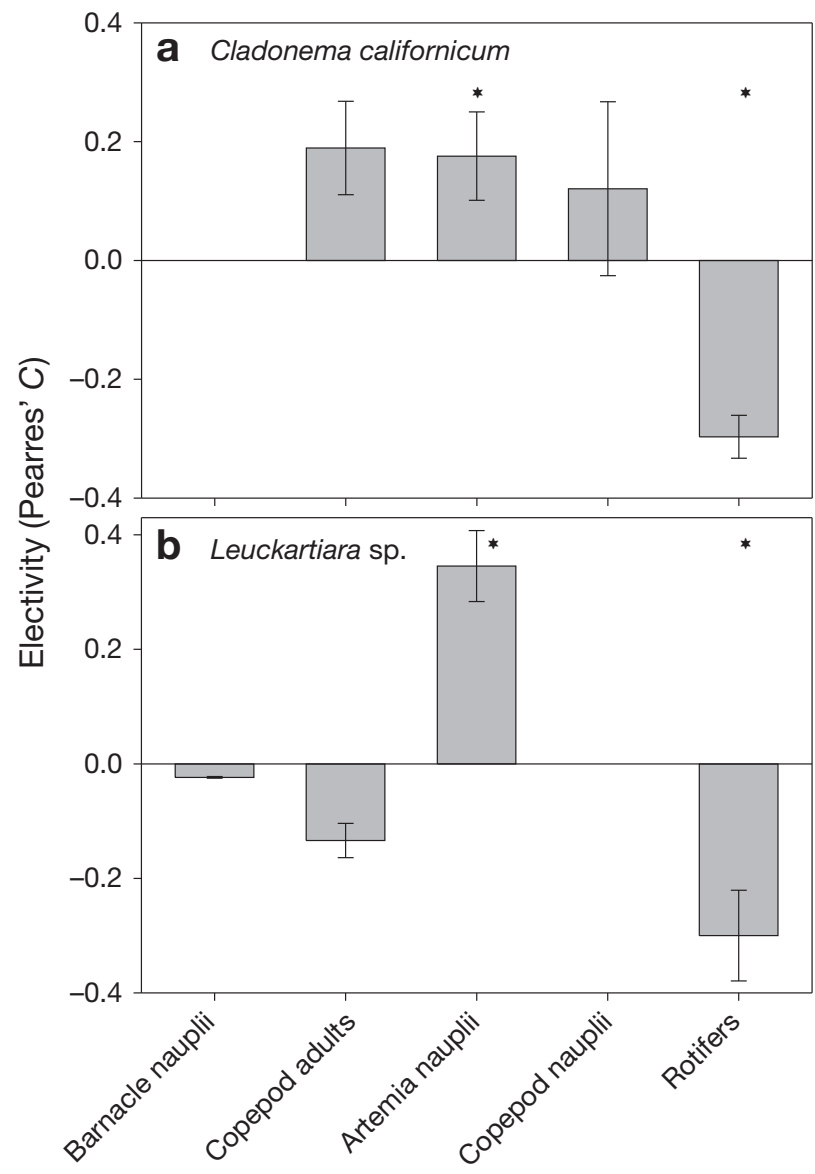

Fig. 4. Cladonema californicum and Leuckartiara sp. Pearres' electivity indices for mixed prey assemblage study for (a) C. californicum and (b) Leuckartiara sp. Error bars represent \pm SE among medusae. (*) Values significantly different from zero $(\mathrm{p}<0.05)$

It took Cladonema californicum just under $1 \mathrm{~min}$ to transfer captured prey to their manubrium and redeploy their tentacle (Fig. 7a). Handling times did not differ significantly among adult and naupliar copepods and Artemia nauplii (ANOVA, p > 0.05; barnacles were not included in the analysis because only one was captured), despite a near order of magnitude difference in the sizes (nauplii $=350 \mu \mathrm{m}$, adults $=1100 \mu \mathrm{m}$ in length). It took Leuckartiara sp. between 1 and 2 min to transfer each type of crustacean prey (Fig. 7b) and 7 min to transfer small hydromedusan prey.

\section{Nematocyst assemblage}

Two types of nematocysts were identified on the tentacles of Cladonema californicum. The most abundant were smaller desmonemes, which made up 94.8\% $( \pm 0.02)$ of the total nematocysts (Fig. 8e). They were characterized by tightly coiled tubules (Fig. 8d), which
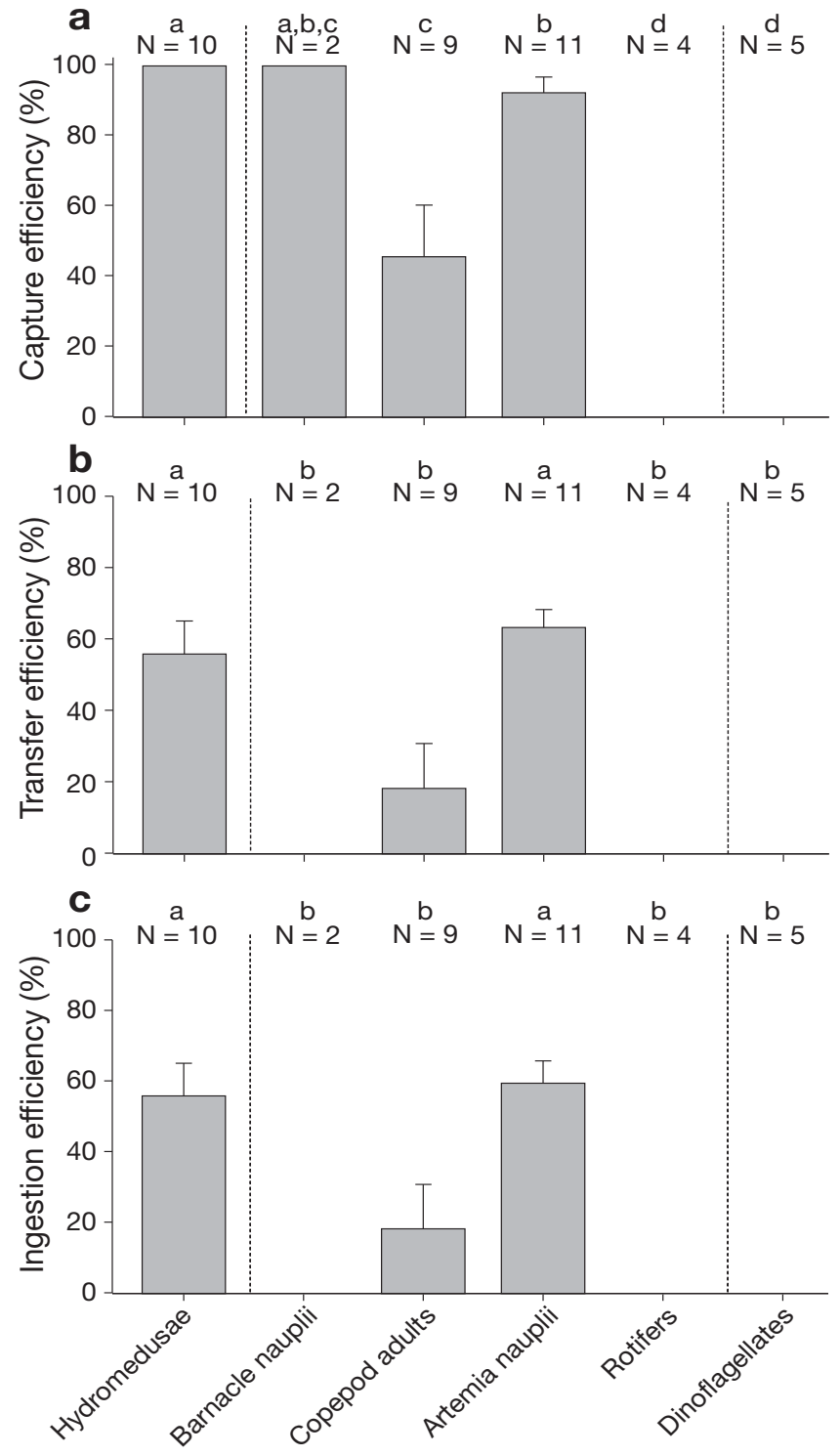

Fig. 5. Leuckartiara sp. Average (a) capture efficiencies, (b) transfer efficiencies and (c) ingestion efficiencies of Leuckartiara sp. fed different prey types. $\mathrm{N}=$ number of medusae observed (observational unit); however, each medusa had several interactions with each prey type. Vertical dashed lines separate prey groups used for each diet; species between lines were a mixed species diet. Efficiencies of prey with the same letter designation did not significantly differ (MannWhitney Rank Sum test, $p>0.05)$. Error bars represent SE

entangled and adhered to prey (Östman et al. 1991). Also present, but less abundant, were large stenoteles, with large shafts with predominant spines that were easily seen inside the undischarged capsules (Table 1, Fig. 8c,e). The cnidocils were highly clustered along the tentacle (variance:mean ratio of density $=4.1 \pm 1.2$ ) arranged in nematocyst batteries. The tentacles of Leuckartiara sp. only contained one type of nematocyst, haploneme euryteles (Fig. 8b), which were ran- 

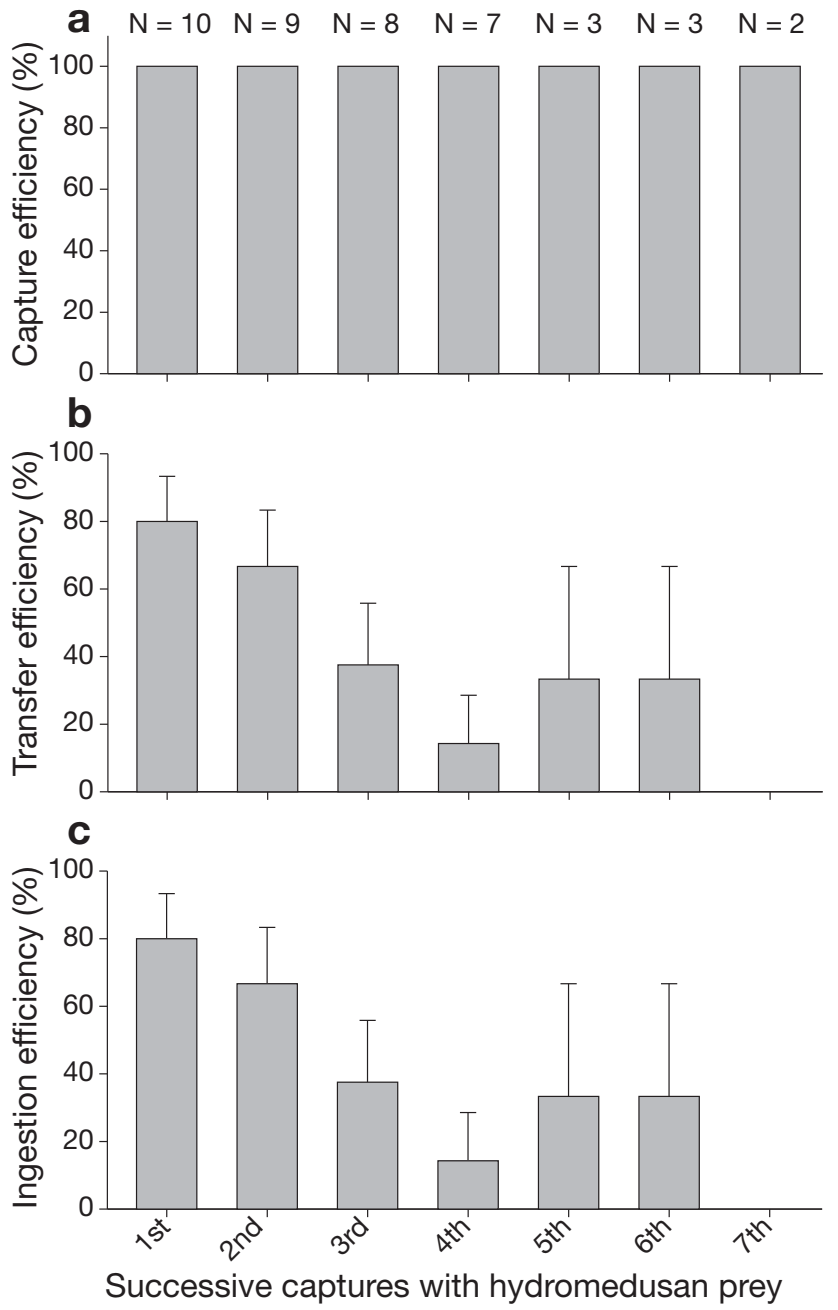

Fig. 6. Leuckartiara sp. Average (a) capture efficiencies, (b) transfer efficiencies and (c) ingestion efficiencies of Leuckartiara sp. after being fed successive hydromedusan prey encountered within the vessel. $\mathrm{N}=$ number of medusae observed (observational unit); however, each medusa had several interactions with each prey type. Error bars represent SE

domly distributed along the tentacle, i.e. not arranged in batteries (variance:mean ratio $=0.54 \pm 0.42$ ) (Fig. 8a). These respective nematocyst characteristics are consistent with those previously described for both C. californicum and Leuckartiara sp. (Russell 1938, Schuchert 2006).

\section{DISCUSSION}

\section{Mechanisms of prey selection}

Our results and previous observations (Purcell 1981, Greene 1986, Colin et al. 2005, Hansson \& Kiørboe 2006b) indicate that prey selection by ambush-foraging medusae is determined by the interaction of 3 pri-

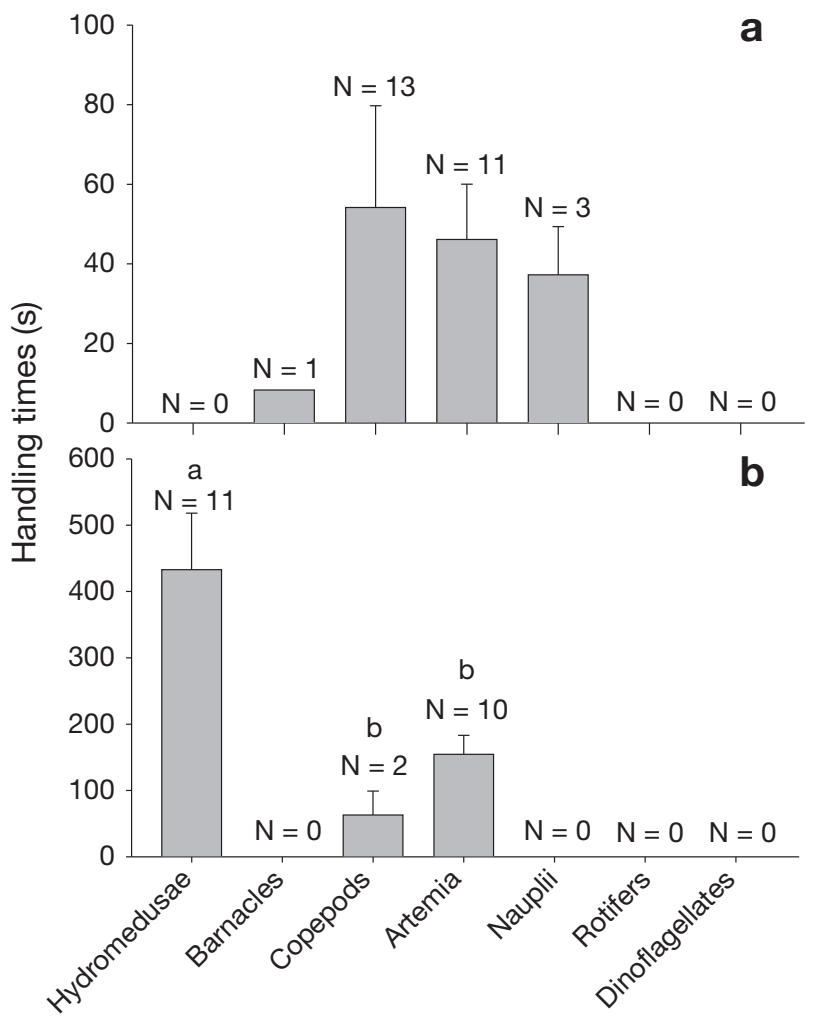

Fig. 7. Cladonema californicum and Leuckartiara sp. (a) C. californicum and (b) Leuckartiara sp. prey-specific handling time (elapsed time from prey capture to prey ingestion); $\mathrm{N}=$ replicate C. californicum or Leuckartiara sp. Handling times with the same letter designation did not differ significantly (MannWhitney Rank Sum test, $\mathrm{p}>0.05)$. Post-hoc tests were not performed for C. californicum since handling times did not differ significantly among prey (ANOVA, p > 0.05; barnacles were not included in the analysis because only one was captured). Error bars represent SE

mary mechanisms. First, encounter rates determine the frequency with which different prey types contact the tentacles of ambush-foraging medusae. Encounter rates are directly related to prey size and swimming velocity (Gerritsen \& Strickler 1976, Pastorok 1981) and result in ambush-foraging predators encountering larger, faster-swimming prey over smaller, slower prey (Pastorok 1981, Purcell 1981, Greene 1986).

The second mechanism, retention capabilities of the tentacle (quantified here as transfer efficiencies), appears to be more important than encounter rates at determining prey selection of large metazoan prey (Hansson \& Kiørboe 2006b) (Figs. 3 \& 5). Here, ingestion efficiency was highly size-dependent and both Cladonema californicum and Leuckartiara sp. were most proficient at ingesting medium-sized crustacean prey with poor escape abilities (i.e. Artemia sp.). As prey size and escape abilities increased (e.g. copepods and barnacle nauplii), transfer efficiencies decreased. 

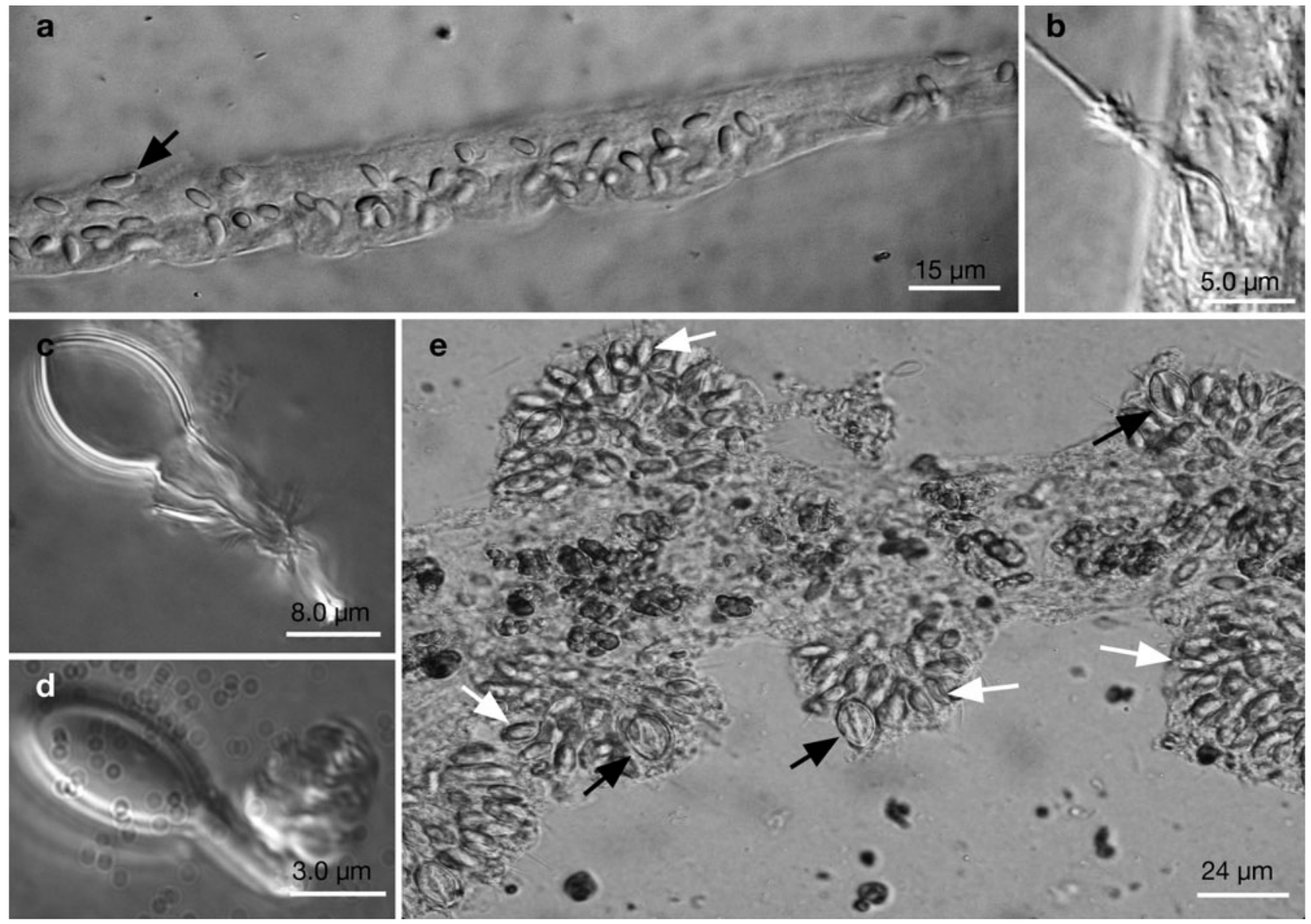

Fig. 8. Cladonema californicum and Leuckartiara sp. (a) Tentacle section of Leuckartiara sp. with uniformly distributed undischarged eurytele nematocysts (arrow). Discharged (b) eurytele nematocyst of Leuckartiara sp. and discharged (c) stenotele and (d) desmoneme of C. californicum. (e) Tentacle section of C. californicum with undischarged (black arrow) stenotele and (white arrow) desmoneme nematocysts arranged in batteries along the tentacle

Similarly, retention abilities limited the ingestion of barnacle nauplii by Sarsia tubulosa (Hansson \& Kiørboe 2006b) and the ingestion of copepods by Aglaura hemistoma (Colin et al. 2005).

Finally, prey selection was also strongly influenced by prey recognition, an active mechanism of prey selection (Pastorok 1981). In particular, Cladonema californicum and Leuckartiara sp. were non-reactive to the small prey they encountered, and, consequently, they did not capture or ingest rotifers and dinoflagellates. C. californicum was also non-responsive to hydromedusae. Similar active dietary choice has been observed in other ambush-foraging predators including Aglaura hemistoma, which avoided ingesting nonmotile prey (Colin et al. 2005); Rathkea octopunctata, which avoided phytoplankton (R. Waggett et al.

Table 1. Cladonema californicum and Leuckartiara sp. Nematocysts (mean $\pm \mathrm{SD}, \mathrm{N}$ in parentheses) found on the tentacles of C. californicum and Leuckartiara sp. NA = not applicable due to coiling of tubule

\begin{tabular}{|lccccc|}
\hline & $\begin{array}{c}\text { Capsule width } \\
(\mu \mathrm{m})\end{array}$ & $\begin{array}{c}\text { Capsule length } \\
(\mu \mathrm{m})\end{array}$ & $\begin{array}{c}\text { Tubule length } \\
(\mathrm{mm})\end{array}$ & $\begin{array}{c}\text { Nematocyst density } \\
\left(\text { no. } 130 \mathrm{~m}^{-2}\right)\end{array}$ & $\begin{array}{c}\text { Variance/mean } \\
\text { of density }\end{array}$ \\
\hline $\begin{array}{l}\text { Cladonema californicum } \\
\text { Desmonemes }\end{array}$ & $3.4 \pm 0.30(13)$ & $6.8 \pm 0.44(13)$ & $\mathrm{NA}$ & $11.7 \pm 6.8(7)$ & $4.06 \pm 1.24(7)$ \\
$\begin{array}{l}\text { Stenoteles } \\
\text { Leuckartiara sp. } \\
\text { Euryteles }\end{array}$ & $8.4 \pm 0.62(13)$ & $12.0 \pm 0.74(13)$ & $0.15 \pm 0.08(25)$ & & \\
& $2.6 \pm 0.20(20)$ & $5.7 \pm 0.60(20)$ & $0.10 \pm 0.05(25)$ & $9.9 \pm 2.3(10)$ & $0.54 \pm 0.42(10)$ \\
\hline
\end{tabular}


unpubl. data); and Bougainvillia sp., Sarsia tubulosa and Hybocodon sp., which avoided dinoflagellates (S. P. Colin unpubl. data).

\section{Nematocysts and prey selection}

While encounter rates are largely affected by tentacle characteristics such as spacing, length and number (Mills 1981, Madin 1988), capture and transfer efficiencies are primarily determined by nematocyst properties (Purcell \& Mills 1988, Thorington \& Hessinger 1988, 1996, Colin \& Costello 2007). Though impossible to confirm without observing actual nematocyst-prey interactions, we suggest that capture efficiencies were most likely influenced by the failure of nematocysts to discharge during encounters with small or unrecognized prey. Thus, only items recognized as food were captured. Consequently, prey selection patterns of ambush-foraging hydromedusae have the potential to be highly specific, since nematocyst discharge may be highly sensitive to different mechanical thresholds and chemical cues (Thorington \& Hessinger 1988, Watson \& Hessinger 1991).

Nematocyst complements of hydromedusae appear to be related to prey selection patterns (Purcell \& Mills 1988). The different transfer efficiencies of Cladonema californicum and Leuckartiara sp. were reflected in differences in nematocyst densities and arrangements. The nematocysts of $C$. californicum were clustered into nematocyst batteries, which may assist in the retention of large prey (Thorington \& Hessinger 1996). C. californicum possessed entangling desmonemes, thought to be important for capturing crustaceans, and penetrating stenoteles (Östman et al. 1991), thought to deliver toxins to captured prey (Purcell \& Mills 1988). This assemblage was similar to that described for Sarsia tubulosa, another copepod predator (Purcell \& Mills 1988). In contrast, Leuckartiara sp. only possessed penetrating euryteles, which were more widely dispersed along the tentacle than those of C. californicum. Although both euryteles and stenoteles penetrate prey (Purcell \& Mills 1988, Östman et al. 1991), the different selection patterns of C. californicum and Leuckartiara sp. suggest that different penetrating nematocysts are associated with different prey selection.

\section{Medusan morphology and prey selection patterns}

Prey selection patterns among ambush-foraging medusae vary greatly (Mills 1981, Purcell \& Mills 1988, Toonen \& Fu-Shiang 1993, Costello \& Colin 2002). Morphological variations observed among hydromedusan species may sufficiently impact the feeding pro- cess, thereby accounting for the different prey selection patterns observed among certain species. Depending on the size of the prey selected, different feeding mechanisms influence prey capture by ambush predators. For small prey $(<100 \mu \mathrm{m})$, encounter rates mostly limit ingestion (Gerritsen \& Strickler 1976, Pastorok 1981). Consequently, we would expect to see tentacle traits that maximize encounter rates, such as high tentacle densities and surface areas, to dominate the tentacle morphology of medusae that select small prey (Gerritsen \& Strickler 1976, Madin 1988, Hansson \& Kiørboe 2006a). In contrast, transfer efficiencies are most limiting for medusae that select large crustacean prey (Hansson \& Kiørboe 2006a). For these species, traits that maximize the retention of captured prey should dominate tentacle morphology. Concentrating many nematocysts on few tentacles has been observed for the copepod predator Sarsia tubulosa (Daan 1986, Purcell \& Mills 1988, Costello \& Colin 2002) and resembles our observations of Cladonema californicum. We believe that variations in morphology can alter encounter and transfer efficiencies sufficiently to vary prey selection. In conjunction with diet recognition, these mechanisms may contribute to the diverse prey selection patterns observed among ambush-foraging hydromedusae.

\section{Feeding mechanisms and predatory impact}

Despite often high abundances, ambush-foraging hydromedusae have only a limited trophic impact (e.g. Daan 1986). Their feeding mechanisms, along with their small sizes, probably limit their predatory impact in 2 ways. First, the maximum feeding rates of ambush-foraging medusae are limited by the transfer and handling rates of prey (maximum ingestion $=$ transfer rate $^{-1}$; Hansson \& Kiørboe 2006a). However, maximum rates are achievable only with high prey densities when encounter rates are not limiting - and before the guts of the medusae become full. Once the guts are full, digestion time limits maximum ingestion rates (ingestion = digestion time ${ }^{-1} ;$ Hansson \& Kiørboe 2006a) . Digestion times range in magnitude from $30 \mathrm{~min}$ to several hours depending on prey type (e.g. Matsakis \& Conover 1991, Båmstedt \& Martinussen 2000). Second, the highly diverse prey selection patterns observed among ambush species result in generally non-overlapping diets of co-occurring ambush species, i.e. niche separation (Costello \& Colin 2002). Little dietary overlap among co-occurring species would prevent ambush-foraging medusae from exerting a combined predatory pressure on specific prey populations, thereby limiting their overall trophic impact. Based on these constraints imposed by their size and feeding strategy, 
we would expect ambush-foraging hydromedusan populations to have low trophic impacts, except, perhaps, for the short, intermittent periods when the population densities reach maximum levels (Toyokawa \& Terazaki 1994, Daly-Yahia et al. 2003).

\section{Are hydromedusae likely micrograzers?}

It has been hypothesized that small ambush-foraging hydromedusae may potentially be important grazers of microplankton (Colin et al. 2005). However, there are very few observations of small hydromedusae feeding on protist prey (Colin et al. 2005). In fact, some ambush-foraging hydromedusae avoid feeding on protist prey (Figs. 3 to 5), such as Rathkea octopuntata (R. Waggett et al. unpubl. data), and Bougainvillia sp., Sarsia tubulosa and Hybocodon sp. (S. P. Colin unpubl. data). According to optimal foraging theory (e.g. MacArthur \& Pianka 1966, Schoener 1971), foragers should feed on the most energetically profitable prey (i.e. net energy gain per unit time). The energy gained from a diet is usually proportional to the volume of the prey ingested. As prey increase in size, their energy content increases exponentially (roughly as a cube of their length). For ambush-foraging medusae, the amount of time over which the energy is gained is determined by the time elapsed between encounters (= encounter rate $^{-1}$ ) plus the handling time for each prey item, neither of which vary greatly with prey size as a consequence of the mechanics of ambush feeding (Gerritsen \& Strickler 1976, Pastorok 1981, Greene 1986, Colin et al. 2005, Hansson \& Kiørboe 2006b) (Fig. 7). Consequently, for ambush-foraging medusae, energetic profitability is dominated by the energy gained term, so larger prey are likely to be much more profitable than small prey. In fact, a hydromedusa would have to eat $>38$ Branchionus sp. rotifers, 800 tintinnids or 10000 dinoflagellates to get the equivalent carbon of 1 adult Acartia hudsonica copepod (assuming equal assimilation efficiency; based on carbon estimates from Verity 1985, Durbin \& Durbin 1992, Rothhaupt 1995, Tang \& Taal 2005). It would take ambush-foraging medusae more than $1 \mathrm{wk}$ of feeding at maximum ingestion rates to eat enough dinoflagellates to equal the energy in a copepod. Thus, in coastal systems where zooplankton abundances are often high, it may be energetically unfavorable for ambush-foraging hydromedusae, with such limiting collecting ability, to ingest microplankton. In fact, capturing and ingesting small prey may interfere with and reduce feeding on larger prey. This may not be true for oligotrophic systems where prey are often limiting. For example, Aglaura hemistoma, a small ( $<3 \mathrm{~mm})$ trachymedusa, captured and ingested prey ranging from dinoflagellates to adult copepods (Colin et al. 2005). However, A. hemistoma is found in highly oligotrophic systems and has extraordinarily short handling times of $<0.05 \mathrm{~s}$. Hence, use of microplankton food appears to be a special case rather than the rule among ambush-foraging hydromedusae.

\section{CONCLUSIONS}

Differences in encounter rates (influenced by prey characteristics and medusan tentacle deployment), capture efficiencies (influenced by active medusan choice and nematocyst properties) and transfer efficiencies (influenced by gut fullness) all contribute to hydromedusan prey selection. The diverse, and in some cases, restricted, dietary niches of ambush-foraging hydromedusae reflect the species-specific selective forces acting at each of these levels within the predation process. Additionally, the constraints on these processes may limit the predatory impact of ambushforaging hydromedusae and prevent them from being capable of influencing plankton communities at similar levels to those of cruising medusae.

Acknowledgements. We are grateful for the support of the National Science Foundation (OCE-0351398 and -0623534 awarded to S.P.C. and OCE-0350834 awarded to J.H.C.) and the Roger Williams University Research Foundation. We also thank J. Titelman and R. Waggett for the valuable comments on the manuscript and S. Spina and the jellyfish crew at the New England Aquarium for their generous support with animals.

\section{LITERATURE CITED}

Båmstedt U, Martinussen MB (2000) Estimating digestion rate and the problem of individual variability, exemplified by a scyphozoan jellyfish. J Exp Mar Biol Ecol 251:1-15

Colin SP, Costello JH (2007) Functional characteristics of nematocysts found on the scyphomedusa Cyanea capillata. J Exp Mar Biol Ecol 351:114-120

Colin SP, Costello JH, Graham WM, Higgins J (2005) Omnivory by small cosmopolitain hydromedusae Aglaura hemistoma. Limnol Oceanogr 50:1264-1268

> Costello JH (1988) Laboratory culture and feeding of the hydromedusa Cladonema californicum Hyman (Anthomedusa: Cladonemidae). J Exp Mar Biol Ecol 123:177-188

- Costello JH, Colin SP (1994) Morphology, fluid motion and predation by the scypohmedusae Aurelia aurtia. Mar Biol 121:327-334

Costello JH, Colin SP (2002) Prey resource use by coexistent hydromedusae from Friday Harbor, Washington. Limnol Oceanogr 47:934-942

> Daan R (1986) Food intake and growth of Sarsia tubulosa (SARS, 1835), with quantitative estimates of predation on copepod populations. Neth J Sea Res 20:67-74

Dabiri JO, Colin SP, Costello JH, Gharib M (2005) Flow patterns generated by oblate medusan swimmers: in situ observation and analysis. J Exp Biol 208:1257-1269

Daly-Yahia MN, Goy J, Daly-Yahia-Kefi O (2003) Distribution 
and ecology of medusae and scyphomedusae (Cnidaria) in Tunis Gulf (SW Mediterranean). Oceanol Acta 26:645-655

Durbin EG, Durbin AG (1992) Effects of temperature and food abundance on grazing and short-term weight change in the marine copepod Acartia hudsonica. Limnol Oceanogr $37: 361-378$

Gerritsen J, Strickler J (1976) Encounter probabilities and community structure in zooplankton: a mathematical model. J Fish Res Board Can 34:73-82

Greene CH (1983) Selective predation in freshwater zooplankton communities. Int Rev Gesamten Hydrobiol 68: 297-315

Greene CH (1986) Patterns of prey selection: implications of predator foraging tactics. Am Nat 128:824-839

Hansson LJ, Kiørboe T (2006a) Effects of large gut volume in gelatinous zooplankton: ingestion rate, bolus production and food patch utilization by the jellyfish Sarsia tubulosa. J Plankton Res 28:937-942

Hansson LJ, Kiørboe T (2006b) Prey-specific encounter rates and handling efficiencies as causes of prey selectivity in ambush feeding hydromedusae. Limnol Oceanogr 51: 1848-1858

Hansson LJ, Moeslund O, Kiørboe T, Riisgaard HU (2005) Clearance rates of jellyfish and their potential predation impact on zooplankton and fish larvae in a neritic ecosystem (Limfjorden, Denmark). Mar Ecol Prog Ser 304:117-131

Holling CS (1959) The components of predation as revealed by a study of small mammal predation of the European pine sawfly. Can Entomol 91:293-320

MacArthur RH, Pianka ER (1966) An optimal use of a patchy environment. Am Nat 100:603-609

Madin LP (1988) Feeding behavior of tentaculate predators: in situ observations and conceptual model. Bull Mar Sci 43:413-429

Matsakis S, Conover RJ (1991) Abundance and feeding of medusae and their potential impact as predators on other zooplankton in Bedford Basin (Nova Scotia, Canada) during spring. Can J Fish Aquat Sci 48:1419-1430

Mills CE (1981) Diversity of swimming behaviors in hydromedusae as related to feeding and utilization of space. Mar Biol 64:185-189

Östman C, Piraino S, Kem W (1991) Nematocysts of the Mediterranean hydroid Halocordyle disticha. Hydrobiologia 216-217:607-613

Passano LM (1973) Behavioral control systems in medusae: a comparison between hydro- and scyphomedusae. Publ Seto Mar Biol Lab 20:615-645

Pastorok RA (1981) Prey vulnerability and size selection by Chaoborus larvae. Ecology 62:1311-1324

Editorial responsibility: Andrew Brierley, St. Andrews, UK
Pearre S (1982) Estimating prey preference by predators: uses of various indices, and a proposal of another based on $\chi^{2}$. Can J Fish Aquat Sci 39:914-923

Purcell JE (1981) Feeding ecology of Rhizophysa eysenhardti, a siphonophore predator of fish larvae. Limnol Oceanogr 26:424-432

> Purcell JE (1991) A review of cnidarians and ctenophores feeding on competitors in the plankton. Hydrobiologia 216-217:335-342

Purcell JE, Mills CE (1988) The correlation between nematocyst types and diets in pelagic hydrozoa. In: Hessinger DA, Lenoff HM (eds) The biology of nematocysts. Academic Press, San Diego, CA, p 463-485

Rothhaupt KO (1995) Algal nutrient limitation affects rotifer growth rate but not ingestion rate. Limnol Oceanogr 40: 1201-1208

Russell FS (1938) On the nematocysts of hydromedusae. J Mar Biol Assoc UK 23:145-165

Schoener TW (1971) Theory of feeding strategies. Annu Rev Ecol Syst 2:369-404

Schuchert P (2006) The European athecate hydroids and their medusae (Hydrozoa, Cnidaria): Capitata Part 1. Rev Suisse Zool 11:325-410

Tang KW, Taal M (2005) Trophic modification of food quality by heterotrophic protists: species-specific effects on copepod egg production and egg hatching. J Exp Mar Biol Ecol 318:85-98

Thorington GU, Hessinger DA (1988) Control of cnida discharge: I. Evidence for two classes of chemoreceptors. Biol Bull (Woods Hole) 174:163-171

Thorington GU, Hessinger DA (1996) Efferent mechanisms of discharging cnidae: I. Measurements of intrinsic adherence of cnidae discharged from tentacles of the sea anemone, Aiptasia pallida. Biol Bull (Woods Hole) 190:125-138

Titelman J, Hansson LJ (2006) Feeding rates of the jellyfish Aurelia aurita on fish larvae. Mar Biol 149:297-306

Toonen RJ, Fu-Shiang C (1993) Limitations of laboratory assessments of coelenterate predation: container effects on the prey selection of the Limnomedusa, Proboscidactyla flavicirrata (Brandt). J Exp Mar Biol Ecol 167:215-235

Toyokawa M, Terazaki M (1994) Seasonal variation of medusae and ctenophores in the innermost part of Tokyo Bay. Bull Plankton Soc Jpn 41:71-75

Verity PG (1985) Grazing, respiration, excretion and growth rates of tintinnids. Limnol Oceanogr 30:1268-1282

Watson GM, Hessinger DA (1991) Chemoreceptor-mediated elongation of stereocilium bundles tunes vibration-sensitive mechanoreceptors on cnydocyte-supporting cell complexes to lower frequencies. J Cell Sci 99:307-316

Submitted: May 16, 2008; Accepted: September 23, 2008 Proofs received from author(s): December 15, 2008 